and only offers a limited list for oral equivalence adds to the confusion. There is a need for a broader consensus in this area in order that clinicians are better informed as to appropriate prescribing.

Foster. P. (1989) Neuroleptic equivalence. The Pharmaceutical Journal, September, 431-432.

SchulZ, P., REY, M., DICK. P. \& TISSOT, R. (1989) Guidelines for the dosage of neuroleptics. II: Changing from dally oral to long acting injectable neuroleptics. International Clinical Psychopharmacology. 4, 105-114.

HARRY DOYLE, Northwick Park Hospital, Harrow HA1 3UJ

\section{Patient advocacy}

Sir: Klijnsma (Psychiatric Bulletin, 1993, 17, 230-231) has described the Dutch model of patient advocacy. We report a case in which potential problems of the advocacy are raised.

$N$ is 55 . He has chronic schizophrenia, partially improved by anti-psychotic medication. An attempt to reduce medication in 1993 caused psychotic exacerbation and disturbed, aggressive behaviour. $N$ lacks insight, denying he is ill. He has functional blindness, attributed to the medication which he strongly resists. He is on section 3 of the Mental Health Act and in the past 12 months had this upheld by the hospital managers and a mental health review tribunal. A second opinion doctor supported his current treatment.

When $\mathrm{N}$ requested to stop treatment, a nurse arranged for an NSF (National Schizophrenia Fellowship) advocate to meet him. It was suggested that another responsible medical officer (RMO) take over his care, and the advocate helped $\mathrm{N}$ to write to hospital management requesting this. It was pointed out by nursing staff (although interestingly never by $\mathrm{N}$ or the advocate) that a right to this is contained within the government White Paper Health of the Nation. $\mathbf{N}$ believed that alternative psychiatrists would take him off his anti-psychotics.

The clinical team had a series of meetings with $\mathrm{N}$, involving the advocate, to try to resolve his agitation and confusion over his current treatment. Consultation confirmed that no other RMO was willing to take over N's care; all those approached supporting a continuation of his depot medication.

During a joint meeting with the advocate, $\mathrm{N}$ made allegations that his consultant had murdered patients, and he witnessed horses being killed on the ward. He claimed to have psychiatric training and dismissed his treatment, saying it was an attempt to murder him. The advocate had three meetings with $\mathbf{N}$ acknowledged that this was a 'nightmare case', and withdrew.
This advocate was sensitive to the dangers of unrealistic acceptance of N's accusations. The disruption to his care was minimal. The careful long-term relationship built between such a patient and his mental health professionals may be jeopardised in this situation. Had this advocate followed the model of 'true advocacy', in which the patient's right to make his decisions prevails, the advocate would have supported the patient's complaints against his clinical team. However, where (as occurs in schizophrenia) these concerns relate to paranoid delusions involving staff, becoming involved may reinforce their validity for the psychotic patient.

There is no uniform, structured approach to patient advocacy in the UK. The Dutch system appears to have limitations. The authors suggest that mental health professionals need to work with advocates in complex cases, to protect the patient's right to receive proper treatment, and have his/her concerns properly considered.

R. MACPHERSON and B. H. ANSTEE, Coney Hill Hospital, Coney Hill, Gloucester GLA 7QJ

\section{The contribution of medical representatives to consultant psychiatrists' understanding and use of psychotropic medication}

Sir: I have recently carried out a small study to try to determine whether the work of medical representatives ('drug reps') contributes in a significant way to consultant psychiatrists' understanding and use of psychotropic drugs.

In March and April 1994, I sent out a 15-item questionnaire, to be filled in anonymously, to a total of 60 consultant psychiatrists at hospitals in, and close to, London; 33 consultants (55\%) had returned the questionnaires by the end of April. It is self-evident that the sample is unlikely to be representative of the national picture.

The responders segregate into three categories: consultants who agree to see drug reps and who also accept gifts from them $(n=16)$; consultants who agree to see drug reps, but refuse gifts from them $(n=6) ;$ and consultants who totally refuse to see drug reps $(n=11)$.

As sources of information about psychotropic drugs, drug reps are considered extremely important by none, very important by $9 \%$ fairly important by $36 \%$, and not important at all by some $51 \%$ of responders.

Sixty-seven per cent of responders do meet reps from time to time, while $33 \%$ totally refuse to see them. Of those who do see them, 13\% positively encourage their visits and $23 \%$ are happy for them to drop in whenever they happen to be around. Seventy-seven per cent of those who see them require them to make specific appointments. 
Of the activities of reps, imparting information about drugs, obtaining reprints of papers and organising educational conferences are considered very important or fairly important by a total of $72 \%, 64 \%$ and $77 \%$ respectively. Social activities are considered not at all important by at least $95 \%$ of the responders.

The information supplied by drug reps has had the most influence on the prescribing habits of doctors in relation to indications, contraindications, dosage, therapeutic effects, and adverse effects.

There is almost unanimous agreement (86\%), even among the consultants who agree to see them, that drug reps gladly volunteer information that is favourable to their products, but withhold adverse information (77\%).

Sixty-nine per cent of the consultants who accept gifts* are convinced that they have sufficient Ego-strength to resist being influenced by these presents, while $83 \%$ of those who refuse them consider that the cost of these gifts does eventually get incorporated into the cost of medicinal treatments, and that there is a definite, and potentially undermining, ulterior motive in the giving of presents to doctors.

The views of those consultants who agree to see them, regarding the drug reps' priorities, make sobering reading: only $9 \%$ believe that the welfare of patients is extremely important to drug reps, $18 \%$ that it is very important, $50 \%$ that it is fairly important, and 23\% that it is not important at all to reps; whereas between $63 \%$ and $82 \%$ of these consultants are of the opinion that the commercial success of their companies, their commissions and their jobs are extremely important to the reps, far more so than is the welfare of patients or the safe and effective use of drugs by the doctors.

It appears that a person of warm and courteous personality, knowledgeable about psychotropic drugs and endowed with good communication skills is likely to be invited back to another appointment with the consultant. Gender, appearance, and generosity with presents apparently play no part in this process, but persistence may pay off in the end. Most consultants firmly deny any desire to exploit

"It should be carefully stated that these are almost all of trivial value. reps, although one makes the rather chilling statement that he (or she) only sees drug reps "to bleed them for academic support"!

Do drug reps make any real difference then? Would it be just as well for us to master the contents of the British National Formulary and the data sheets? If the pharmaceutical companies were today to discontinue the use of medical representatives, would that leave a 'drug rep-shaped' hole in our hearts, or would we heave a collective sigh of relief?

My overall impression, from these data, is that pharmaceutical companies, through the work of the drug reps, do play a significant and very useful role in our work: they support our educational activities at a time when it is very difficult to obtain essential funds for these and they pass on information which most responders acknowledge does enable our safer and better use of drugs.

This study points out a number of areas in which drug reps could improve their performance, perhaps in the process also improving their image. At the same time, we should permit ourselves a more generous and less paranoid attitude towards them. They are attempting, in the face of enormous obstacles, something that we ourselves would probably find impossible to do for a living; it is extremely unfair that so many doctors treat drug reps almost as criminals. As one of the consultants wrote in his additional comments,

"Drug companies are, in my view, much maligned. They are industries within a capitalist society. What are they supposed to do-keep quiet and wait to be approached? The major scandal is the way many doctors treat drug reps. The contempt that many experience reflects badly on the medical profession".

In the United States, these activities are now diverted to a significant extent from practitioners to large purchasing agencies; that is not a change which would be helpful to psychiatrists in this country.

I am grateful to my friend and colleague, Dr Lenny Fagin, Consultant Psychiatrist, for his vetting of the questionnaire through all the stages of its preparation.

IKECHUKWU O. AZUONYE, Claybury Hospital, Woodford Bridge, Essex IG8 8BY 